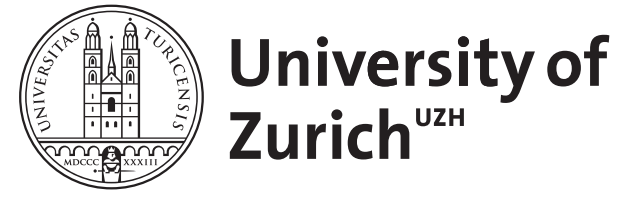

\title{
Nachruf auf Henri Lauener
}

Ferber, Rafael

Abstract: This is an obituary of Henri Lauener (1933-2002)

DOI: https://doi.org/10.1515/kant.2003.023

Posted at the Zurich Open Repository and Archive, University of Zurich ZORA URL: https://doi.org/10.5167/uzh-69845

Journal Article

Published Version

Originally published at:

Ferber, Rafael (2003). Nachruf auf Henri Lauener. Kant-Studien, 94:403-404.

DOI: https://doi.org/10.1515/kant.2003.023 


\section{Nachruf auf Henri Lauener}

Henri Lauener, geb. als Sohn eines Bundesbeamten am 13. Juni 1933 in Bern, Bürger von Krattigen am Thunersee, starb am 28. Oktober 2002 in seiner Heimatstadt. Nach dem Studium von Philosophie, deutscher und französischer Literatur an der Universität Bern und an der Sorbonne in Paris (1957/58) erfolgte 1959 an der Universität Bern bei Hermann Gauss (1902-1966) die Promotion über Hegel und 1967 an derselben Universität die Habilitation über Hume und Kant. 1973 wurde er zum ausserordentlichen Professor an der Universität Bern und nach der 1982 im Verlag C. H. Beck (Beck'sche Schwarze Reihe 503) erschienenen Monographie über W. V. O. Quine im selben Jahr zum ordentlichen Professor ernannt. Gastprofessuren in Helsinki (1969) und in San Diego $(1975,1980)$ ergänzten seine Lehrtätigkeit in der Schweiz. 1993 fand in Bern ein Kolloquium zu seinem 60. Geburtstag statt, das den Titel trug „Transcendentalism and Naturalism“; 1996 erschien zu seinen Ehren eine Festschrift in den Grazer Philosophischen Studien, 44. Ungeachtet familiärer und gesundheitlicher Schicksalsschläge oblag H. Lauener scinen Amtspflichten bis zu der im Jahre 1998 erfolgten Emeritierung. Sein letztes Buch veröffentlichte er im selben Jahr zusammen mit Benito Müller im Academia Verlag: Handlungskontext. Re gelkonforme Verwendung und Bedeutung, St. Augustin 1998. Einige der wichtigsten Aufsätze wurden noch von ihm gesammelt unter dem Titel Offene Transzendentalphilosophie, Boethiana, Forschungsergebnisse zur Philosophie, Band 50, Dr. Kovač, Hamburg 2002. Diesc Offene Transzendentalphilosophie verbindet Quines Naturalismus mit Kants Transzendentalem Apriorismus, allerdings pragmatisch relativiert und gegen Einwände neutralisiert. Eine Grundthese des Offenen Transzendentalismus besteht darin, dass es keine absolut wahren Aussagen in der Wissenschaft und keine absolut gültigen Vorschriften der Moral gibt. Dies ist eine Position, die mit dem Skeptizismus der mittleren Akademie (beginnend mit Arkesilaos, 316-242 v. Chr.) eine gewisse Verwandtschaft aufweist. Der Verstorbene versuchte aber das Beste aus dieser desillusionierten skeptischen Haltung herauszuholen. Auf seiner Todesanzeige war denn auch der Ausspruch von Cicero (106-43 v. Chr.) zu lesen: „La vraisemblance est le terme où s'arrête la portée de mon esprit. Quand à la certitude, je la laisse à ceux qui croient qu'on peut y atteindre, et qui se donnent pour des sages." („Das, was wahr zu sein scheint, ist die Grenze, wo die Tragweite meines Geistes endet. Was die Gewissheit betrifft, so überlasse ich sie denen, die glauben, man könne sic erreichen, und sich für weise ausgeben.")

Am bekanntesten wurde $\mathrm{H}$. Lauener aber wohl als Organisator der Internationalen Kolloquien in Biel, die achtmal von 1973 bis 1988 stattfanden. Dic Akten finden sich publiziert in der von ihm redigierten lnternationalen Zeitsclorift für Philosophie der Erkenntnis, Dialectica. In Verbindung mit diesen Kolloquien gelang es ihm,

Kant-Studien 94. Jahrg., S. 403-404

C. Walter de Gruyter 2003

ISSN 0022-8877 diese Zeitschrift zu einer Plattform der analytischen Philosophie zu machen. Autoren mit einem herausgehobenen Ruf wie Alfred Julius Ayer (1910-1989), Roderick Chisholm (1916-1999), Donald Herbert Davidson (1917-2003), Jaako Hintikka (*1929), Willard Van Orman Quine (1908-2000), John Rogers Searle (*1932) und andere haben darin publiziert. Den wenigsten aber dürfte bekannt sein, dass der Verstorbene früher auch feinfühlige surrealistische Gedichte schrieb, von denen er allerdings später die meisten aus dem Verkehr zurückzog; so habe ich in der Zürcher Zentralbibliothek nur noch den 1963 erschienenen und von Adrian Grütter illustrierten Band „Sommer Indigo“ gefunden; der Verstorbene liebte zudem auch das Boxen und den Jazz. Seine Erinnerungen an Louis Armstrong (1901-1971) sind nachzulesen in: Jazz (Schweiz/A3), 3/1983, S. 32-34). Die hohen formallogischen Präzisionsstandards, die $\mathrm{H}$. Lauener an sich und an andere anlegte, machten den "sturdy champion“ (D. Davidson) der analytischen Philosophie zu einer singulären und respektierten Figur in der Schweizer Philosophieszene der letzten dreissig Jahre.

Rafael Ferber, Universität Luzern und Universität Zürich 